\title{
Análise de Conteúdo e Análise do Discurso: aproximações e afastamentos na (re)construção de uma trajetória
}

\author{
Décio Rocha \\ Bruno Deusdará
}

\section{Introdução}

A história do conhecimento não pode ser contada em uma trajetória linear, como algo que avança gradualmente, dimensionando a relação homem-mundo por intermédio do mero acúmulo progressivo de saberes. Com efeito, a constituição de novos paradigmas científicos impõe uma outra dinâmica, qualquer que seja o campo de saber em que nos situemos. De modo geral, as transformações sucessivas por que têm passado as ciências demonstram irregularidades e rupturas, em vez de um movimento contínuo e retilíneo. Sobretudo no que tange às ciências humanas e sociais, o que se dá não é a mera substituição de um caminho enganoso por caminhos promissores de novas verdades. Trata-se antes de novas perspectivas, que vêm participar da cena, de opções teóricas diversas daquela em relação à qual se produz uma ruptura ou do desejo de redimensionar o objeto de estudo.

Dito isto, é necessário observar que "o gesto inaugural" da chamada Análise do Discurso foi empreendido neste duplo sentido: a construção de um outro olhar sobre as práticas linguageiras e o redimensionamento do objeto de análise * . A trajetória da Análise do Discurso, perspectiva não previamente inscrita no campo do saber $^{1}$, passa pela necessária consolidação das opções teóricometodológicas que vem sendo capaz de realizar, instituindo no novo espaço epistemológico produzido no âmbito dos estudos

"(Gadet, F. \& Hak, T. Poruma
análise automática do discur-
so: uma introdução à obra de
Michel Pêcheux. Campinas:
Unicamp, 1997, $3^{\mathrm{a}}$ ed).

\footnotetext{
${ }^{1}$ Esta expressão é retomada de Maingueneau (1997: 9), opção que desde já vem explicitar a posição que assumimos diante da diversidade de enfoques que se alinham sob a denominação "Análise do discurso".
} 
"(Bardin, Laurence. L'analyse de contenu. Paris: PUF, 1995 Maingueneau, Dominique. Novas tendências em Análise do Discurso. Campinas: Pontes/Unicamp, 1997, $3^{\mathrm{a} e d)}$. da linguagem um processo de rupturas e continuidades em relação a uma certa tradição ${ }^{2}$, o que exige reiterados momentos de legitimação.

\section{Objetivo}

Problematizar esses momentos de legitimação de um dado quadro teórico, ressituando-os à luz dos atuais desafios de uma perspectiva discursiva, é uma questão central aqui. Pretendese, com isso, (re)construir - parcialmente, é claro - a trajetória histórica da Análise do Discurso, observando-se que aspectos teórico-metodológicos da Análise de Conteúdo foram postos em questão pela proposta fundadora de Pêcheux. Sendo assim, nosso objetivo geral neste trabalho é, ao tentar (re)construir esse diálogo ou contraposição, sistematizar minimamente uma reflexão acerca das seguintes questões: i) a que insuficiências da Análise de Conteúdo se procurou responder com uma nova perspectiva discursiva? ii) em que sentido a abordagem da Análise de Conteúdo teria contribuído para as práticas hoje desenvolvidas pela Análise do Discurso?

\section{Metodologia}

O percurso de análise constituído em nossa pesquisa parte de duas obras de referência em Análise de Conteúdo e Análise do Discurso, respectivamente, as de Laurence Bardin e Dominique Maingueneau*. Com base nas obras selecionadas, realizamos uma pesquisa bibliográfica que teve o mérito de expandir a rede de sentidos em cada uma das perspectivas aqui confrontadas com os aspectos identificados como relevantes em cada uma das orientações teórico-metodológicas em discussão. Algumas questões que surgiram no percurso nos indicaram desdobramentos em outras áreas do conhecimento, como a psicologia social, tornando essa experiência muito mais enriquecedora do que havíamos imaginado no início de nosso trabalho.

Como caminho metodológico, a pesquisa bibliográfica era o passo inicialmente projetado para o levantamento de obras de referência em Análise de Conteúdo. Cumprida essa etapa, e de

${ }^{2}$ A tradição a que ora nos referimos diz respeito aos trabalhos em Análise de Conteúdo. Sobre as rupturas e continuidades relativas a tal tradição, remetemos o leitor a "Análise de Conteúdo e Análise do Discurso: o lingüístico e seu entorno", nosso artigo aprovado para publicação na revista D.E.L.T.A, com previsão de publicação para o primeiro semestre de 2006. 
posse de uma listagem minimamente diversa de trabalhos em Análise de Conteúdo, estabelecemos leituras que nos seriam de interesse em um primeiro momento, optando logo em seguida por Análise de conteúdo, de Laurence Bardin. O interesse da obra escolhida pode ser ilustrado pelo que está na contracapa da edição consultada: "Laurence Bardin, professora-assistente de psicologia na Universidade de Paris V, aplicou as técnicas da Análise de Conteúdo na investigação psicossociológica e no estudo das comunicações de massa. Este livro procura ser um manual claro, concreto e operacional desse método de investigação, que pode ser utilizado por psicólogos e sociólogos, qualquer que seja a sua especialidade ou finalidade, e por psicanalistas, historiadores, políticos, jornalistas etc.”. Mais que essa descrição, todavia, o livro atendia a dois requisitos que nos pareciam de grande importância na etapa inicial de pesquisa: de um lado, traçava um panorama do suporte teórico e de metodologias recorrentes em Análise de Conteúdo; de outro, apresentava exemplos práticos de trabalhos levados a cabo segundo a ótica sustentada por esse tipo de análise.

\section{Antecedentes do surgimento da Análise do Discurso}

De forma bastante sintética, pode-se situar o surgimento da chamada Análise do Discurso no fim dos anos 1960, em decorrência de insuficiências de uma análise de texto que se vinha praticando e que se pautava prioritariamente por uma visão conteudista, característica central das práticas de leitura que localizamos nos estudos em Análise de Conteúdo. De um lado, imperava nas ciências humanas e sociais um contexto marcadamente orientado pelos desenvolvimentos de uma dada psicologia social em sua versão behaviorista - perspectiva desenvolvida nos Estados Unidos a partir da primeira metade do século XX; de outro, era claro o predomínio de uma concepção de linguagem influenciada pelos esquemas "informacionais" de comunicação, principalmente aquele elaborado por Roman Jakobson*. Segundo a articulação desses elementos que caracterizaram a abordagem da Análise de Conteúdo, a produção de sentido se refere apenas a

"Jakobson, Roman. Lingüística e comunicação. Sâo Paulo: Cultrix, 1973). 
(Bardin, Laurence. L'analyse de contenu. Ob. cit: 31)
Já a problemática da discursividade surgida com as contribuições da Análise do Discurso propõe o entendimento de um plano discursivo que articula linguagem e sociedade, entremeadas pelo contex to ideológico. A Análise do Discurso, portanto, pretende não instituir uma "nova lingüística", mas consolidar uma alternativa de análise, mesmo que marginal, à perspectiva "tradicional". Um alargamento teórico, uma possibilidade outra, originada de um olhar diferenciado que se lança sobre as práticas linguageiras.

\section{Análise de Conteúdo e Análise do Discurso: aproximações e afastamentos}

Sigamos relacionando os aspectos teórico-metodológicos que foram explicitados em nossas análises, confrontando-os no que tange à construção da trajetória de continuidades e rupturas entre a Análise do Discurso e a Análise de Conteúdo.

\section{Os objetivos da Análise de Conteúdo}

Procurar compreender os objetivos dos estudos desenvolvidos à luz do que se convencionou chamar Análise de Conteúdo quer dizer, acima de tudo, explicitar os rumos assumidos pelas práticas linguageiras de leitura de textos no "campo das ciências". Optar por caminhos que garantam sua legitimação nos conduz à reflexão sobre um pressuposto: uma dada concepção de ciência, herdeira da tradição iluminista, dá sustentação às opções feitas pela Análise de Conteúdo.

Sem pretender, a princípio, configurar-se como doutrinal ou normativa, a Análise de Conteúdo se define como um "conjunto de técnicas de análise das comunicações"* que aposta grandemente no rigor do método como forma de não se perder na heterogeneidade de seu objeto. Nascida de uma longa tradição de abordagem de textos, essa prática interpretativa se destaca, a partir do início do século XX, pela preocupação com recursos metodológicos que validem suas descobertas. Na verdade, trata-se da sistematização, da tentativa de conferir maior objetividade a uma atitude que conta com exemplos dispersos, mas variados, de pesquisa com textos. À guisa de ilustração, vejamos este fragmento: "[como exemplo de Análise de Conteúdo prematura temos] a pesquisa de autenticidade 
feita na Suécia por volta de 1640 sobre os hinos religiosos. Com o objetivo de saber se esses hinos, em número de noventa, podiam ter efeitos nefastos sobre os Luteranos, foi efetuada uma análise dos diferentes temas religiosos, de seus valores e de suas modalidades de aparição (favorável ou desfavorável), bem como de sua complexidade estilística"**

Embora a inovação da Análise de Conteúdo tenha consistido em contribuir com procedimentos "científicos" de legitimação de uma dada técnica de leitura, há algo que permaneceu ao longo do tempo: o objetivo de atingir uma "significação profunda" dos textos: "O que é passível de interpretação? Mensagens obscuras que exigem uma interpretação, mensagens com duplo sentido, cuja significação profunda (a que importa aqui) só pode surgir depois de uma observação cuidadosa ou de uma intuição carismática"* .

Nesse movimento entre a heterogeneidade do objeto e o rigor metodológico é que se percebe em que modelo de ciência se funda a Análise de Conteúdo: um modelo duro, rígido, de corte positivista, herdeiro, como dissemos, de um ideal preconizado pelo Iluminismo. Centra-se, sobretudo, na crença de que a "neutralidade" do método seria a garantia de obtenção de resultados mais precisos. Essa busca se caracteriza inicialmente pelo equívoco clássico de associar análise quantitativa e "objetividade", algo que pode ser observado no grande número de estudos pautados por essa orientação. Mais que isso, há sempre um patrulhamento no sentido de não só preservar a objetividade, mas também afastar qualquer indício de "subjetividade"s que possa invalidar a análise. Aproximar-se da neutralidade equivale, nesses termos, a sustentar-se como ciência. $\mathrm{O}$ analista seria, portanto, um detetive munido de instrumentos de precisão para atingir a significação profunda dos textos.

O rigor, portanto, é o fundamento das contribuições oferecidas pela Análise de Conteúdo, uma vez que, por intermédio dessa característica, afirma-se a possibilidade de ultrapassar as

${ }^{3}$ A noção de subjetividade aqui deve ser compreendida a partir do referencial preconizado pelos estudos em Análise de Conteúdo: explicitação de qualquer forma de implicação do pesquisador com seu objeto de investigação. 
"(:29)

“aparências", os níveis mais superficiais do texto, residindo nesse processo de descoberta a desconfiança em relação aos planos subjetivo e ideológico, considerados elementos de deturpação da técnica. A explicitação de um ponto de vista, qualquer que seja a ótica explicitada, desvirtua os rumos da análise, ou seja, a ideologia é vista como o descaminho da descoberta científica. "Estes dois pólos, desejo de rigor e necessidade de descobrir, de adivinhar, de ir além das aparências, expressam as linhas de força do seu desenvolvimento histórico e o aperfeiçoamento que, atualmente, ainda a faz oscilar entre duas tendências"**

$\mathrm{O}$ fragmento que acabamos de transcrever permite concluir que o tex to se configura tão-somente como uma estratégia de encobrimento de uma "significação profunda" que se deseja recuperar. Na verdade, a principal pretensão da Análise de Conteúdo é vislumbrada na possibilidade de fornecer técnicas precisas e objetivas que sejam suficientes para garantir a descoberta do verdadeiro significado. Nesse sentido, é importante reafirmar aqui a certeza de que haveria um sentido a ser resgatado em algum lugar, e de que o texto seria seu esconderijo. Ao analista, encaminhado pela ciência, caberia descobri-lo: "Metodologicamente, confrontam-se ou completam-se duas orientações: a verificação prudente ou a interpretação brilhante”* .

Chegamos assim à principal questão referente aos objetivos perseguidos pela Análise de Conteúdo: a ultrapassagem da incerteza e o enriquecimento da leitura. O primeiro deles é descrito de acordo com os seguintes aspectos: "o que eu julgo ver na mensagem estará lá efetivamente contido, podendo esta 'visão' muito pessoal ser partilhada por outros?’*'. A caracterização do segundo, por sua vez, não se distancia muito do já visto: "se um olhar imediato, espontâneo, já é fecundo, não poderá uma leitura atenta aumentar a produtividade e a pertinência? Pela descoberta de conteúdos e de estruturas que confirmam (ou infirmam) o que se procura demonstrar a propósito das mensagens, ou pelo esclarecimento de elementos de significações susceptíveis de conduzir a uma descrição de mecanismos de que a priori não detínhamos a compreensão"* .

Nessa formulação, convergem, em grande medida, o objetivo a que se propõe a Análise de Conteúdo e a concepção de ciência sobre a qual ela se alicerça. Aos estudos científicos caberia investigar e descobrir aquilo que a espontaneidade dos “comuns", dos “desprovidos de técnicas seguras de leitura”, não 
é capaz de encontrar. Sob os auspícios da ciência, seria possível apreender a realidade oculta: existiria uma verdade a ser recuperada por intermédio da ciência. Nesse sentido, a concepção de linguagem em jogo reproduz inequivocamente um projeto de representação de um real pré-construído.

\section{Opções metodológicas em Análise de Conteúdo}

Neste item, pretendemos compreender, com base em um exemplo prático de análise nos moldes da Análise de Conteúdo, quais são as preocupações mais relevantes que podem orientar uma pesquisa de acordo com essa perspectiva. Julgamos que, no exemplo apresentado, evidenciam-se opções metodológicas de análise que dão corpo a tal modelo epistemológico, tornando-se possível, desse modo, identificar as concepções subjacentes às etapas da pesquisa e aos resultados a que se pretende chegar.

Assim, a fim de explicitar as posições apresentadas como características de uma abordagem em Análise de Conteúdo, retomamos o exemplo tido como clássico e constante em Bardin, a saber, a análise da simbologia do automóvel, decorrente do seguinte objetivo de pesquisa: "examinar as respostas a um inquérito que explora as relações psicológicas que o indivíduo mantém com o automóvel”*. Diante desse objetivo de pesquisa, são elaboradas duas perguntas, apresentadas como questões abertas, cujas respostas serão submetidas à análise. As perguntas são estas: "1) A que é, geralmente, comparado um automóvel?; 2) Se o seu automóvel lhe pudesse falar, o que é que lhe diria?"*.

Com base no exposto, podemos fazer algumas observações iniciais a respeito de uma certa fundamentação que subjaz à análise pretendida. A primeira se refere à idéia segundo a qual o texto das respostas dadas pelos entrevistados às perguntas formuladas consistiria em uma superfície a ser construída pelo pesquisador, da qual emergiriam "qualidades psicológicas” do entrevistado em relação ao automóvel. Com isso, vê-se uma concepção de linguagem como representação de uma realidade a priori: a linguagem seria apenas um veículo de transmissão de uma mensagem subjacente, sendo a esse conteúdo que se pretende chegar com uma pesquisa em Análise de Conteúdo.

A segunda observação diz respeito à não-problematização das perguntas que compõem o referido instrumento de pes- 
(Rocha, Décio; Daher, M. Del C.; Sant'Anna, V. A entrevista em situação de pesquisa acadêmica: refle. xões numa perspectiva dis. cursiva. Cuiabá: EdUFMT, 2004: 165) quisa e da própria situação de entrevista acadêmica ${ }^{4}$. Isso nos leva a crer que, para os idealizadores da pesquisa, a pergunta importa menos do que as respostas, ou seja, independentemente da pergunta feita, o que importa é ter acesso à relação psicológica do indivíduo com o carro. O referido inquérito é compreendido como uma simples ferramenta capaz de retirar o véu de linguagem que encobre o que realmente se pretende descobrir: a significação profunda que preexiste à pergunta. Assim, manifesta-se "essa crença de que o dito equivale a uma informação com valor de verdade"* .

Uma terceira observação diretamente vinculada à não-problematização do inquérito diz respeito ao fato de que o modo de apresentação das perguntas contribui para um apagamento do pesquisador como co-participante da situação de entrevista. As perguntas são vistas como motivações para fazer emergir "significações profundas", constituindo para estas um efeito de verdade. Ora, uma vez que, de uma perspectiva conteudista, o texto das respostas apenas encobre um real pré-construído, um real da ordem do psicológico existente independentemente da situação de pesquisa que o põe em cena, ele acaba por se constituir como uma verdade tornada absoluta, "autonomizada". Há, aqui, o privilégio da idéia do pesquisador como observador imparcial, em detrimento daquela segundo a qual ele seria responsável por produzir uma intervenção sobre o mundo: o apagamento dos rastros do pesquisador na construção de seu instrumento de pesquisa produz as (pretensas) bases da legitimidade das investigações em Análise de Conteúdo, calcadas nas noções de objetividade e de neutralidade, afastando dos procedimentos de análise as marcas da subjetividade desse pesquisador.

Do exposto, percebe-se que os mecanismos de funcionamento de uma pesquisa em Análise de Conteúdo encenam uma busca ou descoberta dos resultados, e não a construção

${ }^{4}$ Como veremos a seguir, um duplo trabalho de problematização se faz necessário, segundo Rocha, Daher \& Sant'Anna (2004): por um lado, a problematização das perguntas formuladas no bojo de uma entrevista acadêmica, de modo a garantir a distância necessária entre a pergunta que o pesquisador dirige ao entrevistado e a pergunta que formula e dirige a si mesmo, a saber, sua própria pergunta de pesquisa; por outro lado, a problematização da própria situação de entrevista em contexto acadêmico, situação que implica perceber uma distância necessária em relação a outros modos de atualização de entrevistas (por exemplo, entrevistas realizadas por jornalistas noticiando um fato, por apresentadores de programas de televisão etc.). 
de uma análise, que se depreende da não-problematização da pergunta norteadora do inquérito ao ideal de rigor metodológico pretensamente atingido por intermédio das estratégias de apagamento da presença do pesquisador. Desse modo, a ocultação dos rastros do pesquisador, das "marcas de subjetividade", permite que os resultados da investigação sejam apresentados como a descoberta de algo que possui existência independente e anterior à elaboração do projeto de pesquisa. As supostas descobertas validam a cientificidade do aparato teórico-metodológico utilizado, visto que o resultado obtido, a saber, o "desvendamento" de uma realidade dada a priori, legitima-o como tal.

Quanto aos procedimentos de análise das respostas obtidas com o inquérito a que fizemos menção, o pesquisador deve realizar uma primeira leitura dos textos produzidos pelos informantes, chamada de leitura flutuante. A partir dessa primeira leitura, o pesquisador pode transformar suas intuições em hipóteses a serem validadas ou não pelas etapas consecutivas. Das hipóteses formuladas é possível extrair critérios de classificação dos resultados obtidos em categorias de significação. No exemplo referido, procedeu-se ao cruzamento das respostas versando sobre o objeto a que o automóvel era comparado (seres humanos, animais, outros meios de locomoção etc.) ou não, e o tipo de relação mantida pelo indivíduo com o automóvel (puramente funcional, amorosa, de dominação, de dependência, de cuidados, de cumplicidade, de agressividade).

Após o cruzamento das freqüências observadas, a pesquisa apresenta algumas conclusões como as que transcrevemos a seguir:

Efetivamente, essa relação simbólica da mulher com o carro surgiu, nas respostas femininas, ambígua, instável ou dicotomizada, visto que a mulher da nossa sociedade, oprimida pelo símbolo estereotipado e dominante do carro com imagens femininas, somente pode escolher uma das duas soluções: ou adota o estereótipo dominante mas desconfortável, ou inadequado para ela, já que se trata de um estereótipo para uso masculino, ou então, em prejuízo desse estereótipo, cria novas conotações e novas relações simbólicas.*

(Bardin, Laurence. L'analyse de contenu. Ob. cit: 63)

Nesse parágrafo de conclusão da pesquisa realizada com base nos procedimentos da Análise de Conteúdo, a dicotomia entre masculino e feminino se manifesta como algo que preexiste à pesquisa, isto é, como um conhecimento anterior e partilhado que prescindiria de qualquer problematização por 
(Gadet, F. \& Hak, T. Por uma análise automática do discurso. Ob. cit) parte do pesquisador. Não queremos, certamente, permanecer no plano da mera negação (ou ratificação) da referida dicotomia. Entendemos que os modos de construção da oposição entre masculino e feminino nas respostas obtidas precisam ser evidenciados, sob pena de ratificarmos dados produzidos em outras situações de enunciação (como nos discursos do senso comum) e absorvê-los sem qualquer reflexão teórica.

Atentamos para o fato de que o rigor metodológico em Análise de Conteúdo e as estratégias de apagamento das implicações do pesquisador na construção de suas análises são acompanhados de uma não-explicitação da trajetória teórica escolhida para a abordagem de conceitos que sustentam o trabalho de análise realizado, ou mesmo de um apagamento dos conceitos que emergem do referido trabalho. Essa observação, de alguma forma, remete-nos à crítica feita por Pêcheux em relação à não-problematização de elementos teóricos que se mostram relevantes na análise. Com efeito, já no fim da década de 1960, Pêcheux dizia que um ponto de vista científico no tratamento das práticas linguageiras só poderia emergir por intermédio da construção de um objeto de investigação (o discurso) e de um aporte teórico-conceitual*.

\section{O contraponto de uma abordagem discursiva}

A título de exemplificação da distância que se verifica entre as opções feitas pela Análise de Conteúdo e pela Análise do Discurso, produziremos agora um diálogo entre o que foi explicitado até o momento acerca da pesquisa sobre o automóvel e os principais deslocamentos que seriam realizados ao assumirmos um enfoque discursivo. No referido diálogo, centraremos nossa reflexão nos objetivos da pesquisa, na formulação de perguntas, no quadro teórico-metodológico e na natureza dos resultados esperados, explicitando sempre uma questão que tem sido muito produtiva e, por essa razão, central para os desenvolvimentos da pesquisa em Análise do Discurso: as implicações do pesquisador no desenvolvimento de suas atividades.

Em primeiro lugar, consideremos o objetivo do trabalho anunciado: "examinar as respostas a um inquérito que explora as relações psicológicas que o indivíduo mantém com o automóvel". Trata-se de um objetivo assentado em uma certa "concepção de mundo", que, por colocar em cena uma noção de "psicológico" bem ao gosto das teorias essencialistas do indivíduo que floresceram nos Estados Unidos da primeira metade do 
século XX, distancia-se do viés de leituras possibilitadas pela Análise do Discurso, uma vez que o interesse de um enfoque discursivo não pode residir nas "relações psicológicas" de um indivíduo em face de um objeto qualquer pelo simples fato de a Análise do Discurso não compartilhar com a Análise de Conteúdo o mesmo horizonte teórico (concepção de um empírico preexistente ao discursivo e de uma certa concepção de social visto como mera soma das "personalidades individuais"), nem o pressuposto metodológico de que o tex to desvelaria o contexto, isto é, de que a produção linguageira seria reveladora das opiniões e das crenças de um sujeito (homogeneizado e "fracionado" em pensamentos, emoções e comportamentos) a respeito do mundo que o rodeia. Ao contrário, uma abordagem discursiva como a que adotamos não pode negligenciar a espessura que entremeia a relação entre o texto e seu entorno, visando predominantemente ao debate do modo como a enunciação é capaz de inter-relacionar "uma organização textual e um lugar social determinados"*.

Em consonância com o dito acerca do objetivo pretendido, seria outro também o ponto de vista mantido por um enfoque discursivo no que concerne à construção de uma pergunta de pesquisa, procedimento que deveria, da mesma forma, ser problematizado, conforme indicamos como uma das limitações apontadas em relação às práticas em Análise de Conteúdo. Um enfoque discursivo procura evitar a mera busca de uma realidade subjacente a determinadas produções de linguagem, ciente de que toda atividade de pesquisa é uma interferência do pesquisador em uma dada realidade. A problematização a que nos referimos passa necessariamente pelo "descolamento" de duas ordens de realidade: a realidade da pesquisa conduzida (pelo analista) e a dos saberes produzidos durante o inquérito (pelos entrevistados). Com efeito, se o pesquisador se interessa pelas "relações psicológicas" do indivíduo em relação ao automóvel, o desafio será produzir uma distância entre "a pergunta a que somente ele poderá responder", isto é, sua pergunta de pesquisa, e "a pergunta que dirigirá a seus entrevistados". Em outras palavras, não será possível "simplesmente repassar a pergunta de pesquisa aos entrevistados" por intermédio da elaboração de um instrumento qualquer de "sondagem de opinião", como parece ser o caso da formulação "A que é, geralmente, comparado um automóvel?”: a pesquisa acaba reduzida ao instrumento
* (Charaudeau, Patrick \& Maingueneau, Dominique. Dicionário de Análise do Dis. curso. São Paulo: Contexto, 2004: 44) 
(Daher, M. del C. "Quando informar é gerenciar con flitos: a entrevista como estratégia metodológica", The ESPecialist, vol. 19, número especial, 1998)

Silva, R. N. da. A invenção da psicologia social. Petró polis: Vozes, 2005: 16) de sondagem de opinião, dispositivo que banaliza os saberes produzidos pela ação do pesquisador. Uma perspectiva discursiva, ao contrário, problematizaria a necessária distância entre os saberes do pesquisador e os produzidos pela coleta de informação junto aos entrevistados, como o preconiza Daher* ao discutir a elaboração de um roteiro de entrevista em que se evidencie a distância entre as hipóteses formuladas pelo pesquisador e as respostas efetivamente produzidas pelos entrevistados. A investigação da referida distância exige a análise das implicações do pesquisador em sua relação com os entrevistados e com os saberes que pretende explicitar.

É precisamente o entendimento de que o pesquisador, em um dado campo de análise, é co-construtor dos sentidos produzidos que se alteram o lugar em que ele se situa e sua postura de interlocutor em uma determinada situação de pesquisa. Isso, por si só, já é bastante diferente dos pressupostos presentes nas situações de pesquisa que se caracterizam como possibilidade de recolher, de fazer emergir das "profundezas" de um discurso uma verdade a que se procura chegar "cientificamente". Tal ocorre no que diz respeito tanto aos objetivos da pesquisa quanto às perguntas que se formulam, razão pela qual ratificamos a reflexão de Ibañez, reproduzida por Silva, acerca dos dois tipos de crença em que se ancora uma concepção ingênua de social:

[...] a primeira consiste em crer na existência de uma realidade completamente independente de nosso modo de acesso a ela; a segunda, em crer que há um tipo de acesso privilegiado que nos conduziria, graças a uma busca constante de objetividade, à realidade tal como ela verdadeiramente existiria. Em suma, essas duas crenças pressupõem a existência de uma verdade em si na realidade, uma verdade que [...] implicaria um campo de conhecimentos com um discurso neutro capaz de revelar essa verdade*.

Levando adiante nossa tentativa de pensar um paralelo entre o procedimento de trabalho da Análise de Conteúdo e a possível "reedição" de uma postura de pesquisa em Análise do Discurso que, na medida do possível, lhe seja correlata, observaríamos que outra diferença importante reside na identificação dos pressupostos teóricos. Com isso, queremos dizer que, em Análise do Discurso, não basta explicitar possíveis imagens às quais seriam remetidos os automóveis; é preciso que, simultaneamente ao interesse pelas referidas imagens discursivas construídas, haja um desejo de ancorá-las sócio-historicamente. O que se pretende dizer aqui é que um pesquisador em Análise 
do Discurso problematizaria a constituição da pergunta de pesquisa, que não coincidiria, é claro, com a pergunta formulada no inquérito, tendo como interface a ancoragem mencionada. Entre outras razões, podemos, resumidamente, dizer que tal distância decorre de uma dupla espessura do sujeito: pelo viés do materialismo histórico, a presença do ideológico; pelo recurso à psicanálise, a evidência incontornável do inconsciente. Com efeito, um dos pontos nodais de ruptura que permitiram a constituição da Análise do Discurso como disciplina no campo dos estudos da linguagem foi o afastamento da idéia de um sujeito que pudesse fazer escolhas, pois o que interessa ao novo campo de saberes constituído é a descrição das vozes que ressoam, atravessam e abalam a ilusão de unidade que se apresenta nos enunciados, denunciando as falácias de uma ótica que priorize o ideal cartesiano de um sujeito da razão.

Acrescentemos que, ao problematizar a pergunta de pesquisa, um pesquisador em Análise do Discurso não pretenderia fazer emergir uma realidade exterior à linguagem (imagens psicologicamente constituídas como significado profundo). Para a Análise do Discurso, a linguagem não é o reflexo de algo que lhe é exterior. Toda produção de linguagem, portanto, não possui uma motivação outra, constituindo-se, de fato, como produto do encontro entre um eu e um outro, segundo formas de interação situadas historicamente. Não há, em Análise do Discurso, um espaço para formas de determinismo que possam constituir um limite entre um interior (a linguagem) e o seu exterior (o social ou o psicológico). Há sim uma articulação entre esses planos. É desse ponto de vista que um pesquisador em Análise do Discurso elaboraria sua pergunta - uma pergunta que explicitaria seu desejo de intervir (ou a impossibilidade de não intervir) em uma determinada produção de realidade.

Quanto aos possíveis resultados provenientes de uma investigação como a que reformulamos "ficcionalmente", seriam tratados não em termos de um desvendamento, de uma "revelação" de verdades até então mantidas ocultas. As respostas obtidas seriam a mera expressão do modo como o problema de pesquisa se formulou: não podendo descolar-se das situações de enunciação em que se produzem, os enunciados se constituem como o lugar por excelência de embates que nos levam à produção de imagens discursivas de diferentes ordens, sendo o discurso o palco em que tais embates são encenados. 
Dessa forma, um paralelo possível entre as experiências em Análise de Conteúdo e em Análise do Discurso nos leva a uma reflexão instigante, que, por sua vez, nos faz compreender a distância que se verifica entre as duas abordagens no que concerne às implicações do pesquisador e aos pressupostos teóricos.

\section{Como fazer ciência sob a perspectiva discursiva?}

Cabe-nos, agora, dar visibilidade ao diálogo entre as análises relatadas e as problematizações formuladas pela Análise do Discurso como responsáveis pelas rupturas empreendidas. Além disso, parece-nos interessante trazer alguns elementos da reflexão teórica inicial da Análise do Discurso, de modo que se explicite o modo como as opções feitas em sua trajetória se sustentam teoricamente.

O primeiro aspecto a ser observado se refere ao confronto existente em relação ao fazer científico evidenciado em cada uma dessas perspectivas. Na Análise de Conteúdo, constitui-se como ciência uma prática que se pretende neutra no plano do significado do texto, na tentativa de alcançar diretamente o que haveria por trás do que se diz. A relação entre o pesquisador e seu objeto de análise é de distanciamento, mediada por uma abordagem metodológica que garantiria a desejada neutralidade. Além disso, a metodologia assume lugar de destaque, uma vez que as técnicas de validação dos resultados obtidos estão centradas sobretudo na garantia de neutralidade conferida pelo método. Isso se dá, como vimos, pelo apagamento das implicações do pesquisador de Análise de Conteúdo em suas investigações.

Às insuficiências até aqui apontadas se procurou responder, à luz da iniciativa de Pêcheux, com a constituição de um aparato teórico-conceitual que se mostrasse capaz de remodelar os contornos científicos dos estudos da linguagem. O objetivo de Pêcheux, em 1969, é bastante abrangente, pois procura instituir um lugar para a análise discursiva no âmbito dos estudos da linguagem. Enfoca a relação que se estabelece entre a Análise de Conteúdo e a teoria do discurso, procurando apontar os limites oriundos do lugar que a lingüística ocupava desde Saussure como ciência da expressão e de seus meios.

Sendo assim, o surgimento da Análise do Discurso se caracteriza não só por uma reorientação teórica da relação entre o lingüístico e o extralingüístico, como também por uma mu- 
dança da postura do observador em face do objeto de pesquisa. A linguagem, de um ponto de vista discursivo, não pode apenas representar algo já dado, sendo parte de uma construção social que rompe com a ilusão de naturalidade entre os limites do lingüístico e os do extralingüístico. A linguagem não se dissocia da interação social.

Uma perspectiva discursiva que se interessasse pelo estudo da língua como interação já estava prevista nas críticas formuladas por Bakhtin, sobretudo a que se dirigiu ao estruturalismo saussureano. Contrapunha-se, dessa forma, à delimitação do código abstrato como objeto das investigações lingüísticas, ressaltando que a interdição ao estudo das manifestações materiais da língua negligenciaria aspectos fundamentais para as investigações científicas da linguagem.

Ao pautar sua crítica pela iniciativa de traçar um olhar baseado no materialismo histórico sobre a problemática da linguagem, Pêcheux formula a necessidade de perceber o ideológico como elemento constituinte da realidade lingüística. Inaugura, com isso, a possibilidade de observar a relação entre o discursivo e o chamado "extra-discursivo" segundo considerações de ordem distintas das que eram preconizadas pelas abordagens "tradicionais”. Para Pêcheux, portanto, não se trata de dicotomizar o central e o periférico, e menos ainda de estabelecer a primazia de um sobre o outro. Em seu método, pretende-se transformar a natureza das relações entre o lingüístico e o social.

Assim, uma certa tradição que recusa o entendimento do contex to como mero adereço, como moldura da qual se poderia prescindir nas investigações lingüísticas, consolidou-se, a partir da década de 1960, na chamada corrente francesa da Análise do Discurso. Na conformação de um aparato teórico-conceitual, ela retirou da marginalidade dos estudos lingüísticos o discursivo, entendendo-o como espaço de articulação entre linguagem e sociedade.

As referências teóricas mobilizadas pela Análise do Discurso não apenas alteraram o quadro de princípios conceituais e o olhar sobre o objeto, como, de alguma forma, ressituaram o lugar do pesquisador de lingüística entre os demais campos do saber e entre as diversas instituições sociais. Ao lingüista não cabe apenas investigar o que está por trás dos textos (na hipótese de que existiria algo por trás dos textos!), mobilizando instrumentais que validem sua técnica. Segundo a Análise do 
Discurso, cabe ao lingüista, no entendimento da linguagem como forma de intervenção, a construção de saberes sobre o real, algo que exige o diálogo com outras perspectivas e configura uma iniciativa interdisciplinar.

Antes de concluir, gostaríamos de apresentar, com base no modo como conduzimos nossa reflexão, algumas respostas (provisórias, decerto) às duas questões formuladas no início deste artigo. Em primeiro lugar, no que concerne às insuficiências a que a Análise do Discurso procurou responder tendo em vista a limitação das perspectivas dos trabalhos em Análise de Conteúdo, podemos afirmar que uma primeira iniciativa consistiu na revisão de uma certa banalização da relação entre texto e contexto, realizada fundamentalmente por intermédio de uma teorização sobre o discurso calcada na cisão entre o empírico e o discursivo: problematização de uma concepção de linguagem que se afasta da ótica meramente representacional, segundo a qual a produção da realidade se dá em um momento anterior ao da produção das práticas linguageiras.

No que diz respeito à segunda pergunta, relacionada aos aspectos da Análise de Conteúdo que de certo modo teriam preparado os trabalhos em Análise do Discurso, pensamos que o ideal de "rigor metodológico", tão claramente manifestado pela perspectiva da Análise de Conteúdo, pôde funcionar como norte dos trabalhos em Análise do Discurso, a começar pela necessidade de que fossem explicitados da maneira mais precisa possível os caminhos de uma investigação, esforço que não exclui - ao contrário - a explicitação das implicações do pesquisador em relação a seu objeto. A esse respeito, o que se tem conseguido no decorrer das últimas décadas pode ser resumido na seguinte fórmula: os caminhos pelos quais optamos em uma perspectiva discursiva têm indicado que o pesquisador não descobre nenhuma "dimensão oculta" do real (trate-se de um real quer sociológico, quer psicológico), mas participa de uma intervenção sobre o social.

Assim, formalizados os resultados obtidos na presente reflexão, apresentamos no quadro a seguir as conclusões (parciais) que nos parecem caracterizar a distância verificada entre Análise de Conteúdo e Análise do Discurso: 


\section{Quadro-síntese das aproximações e afastamentos entre Análise de Conteúdo e Análise do Discurso}

\begin{tabular}{|c|c|c|}
\hline & ANÁLISE DE CONTEÚDO & ANÁLISE DO DISCURSO \\
\hline Objetivos de pesquisa & $\begin{array}{l}\text { captar um saber que está por } \\
\text { trás da superfície textual }\end{array}$ & $\begin{array}{l}\text { analisar em que perspec- } \\
\text { tivas a relação social de } \\
\text { poder no plano discursivo } \\
\text { se constrói }\end{array}$ \\
\hline Eu pesquisador & $\begin{array}{l}\text { espião da ordem que se pro- } \\
\text { põe a desvendar a subversão } \\
\text { escondida; leitor privilegiado } \\
\text { por dispor de "técnicas" } \\
\text { seguras de trabalho }\end{array}$ & $\begin{array}{l}\text { agente participante de uma } \\
\text { determinada ordem, contri- } \\
\text { buindo para a construção } \\
\text { de uma articulação entre } \\
\text { linguagem e sociedade }\end{array}$ \\
\hline Concepção de texto & $\begin{array}{l}\text { véu que esconde o signifi- } \\
\text { cado, a intenção do autor }\end{array}$ & materialidade do discurso \\
\hline Concepção de linguagem & $\begin{array}{l}\text { reprodução e disseminação } \\
\text { de uma realidade a priori }\end{array}$ & ação no mundo \\
\hline Concepção de ciência & $\begin{array}{l}\text { instrumento neutro de ve- } \\
\text { rificação de uma determi- } \\
\text { nada realidade }\end{array}$ & $\begin{array}{l}\text { espaço de construção de } \\
\text { olhares diversos sobre o real }\end{array}$ \\
\hline
\end{tabular}




\section{Décio Rocha}

Professor Adjunto do Instituto de Letras e do Colégio de Aplicação da Universidade do Estado do Rio de Janeiro, onde ministra as seguintes disciplinas: Lingüística, Análise do Discurso e Língua francesa. Doutor em Lingüística Aplicada pela PUC - São Paulo. Bolsista do CNPq e pesquisador do grupo Atelier nas áreas de linguagem em situação de trabalho e discursos didáticos. Autor de diversos artigos em periódicos nacionais e internacionais. E-mail: rochadm@uol.com.br

\section{Bruno Deusdará}

Professor de Língua Portuguesa da rede do Estado do Rio de Janeiro e mestrando da área de Lingüística do Programa de Pós-Graduação em Letras da Universidade do Estado do Rio de Janeiro (UERJ), no qual elabora dissertação na linha de pesquisa Práticas de Linguagem e Discursividade. E-mail: brunodeusdara@yahoo.com.br

Palavras-chave

Análise do Conteúdo, Aná lise do Discurso, meto. dologia

Key words

Content Analysis, Discour. se Analysis, methodology

Mots-clé

Analyse de Contenu, Analyse du Discours, méthodologie

Recebido em $15 / 10 / 2005$

Aprovado em $13 / 11 / 2005$

\section{Resumo}

O presente artigo foca a construção de uma perspectiva discursiva à luz das insuficiências do trabalho desenvolvido pela Análise do Conteúdo. Seus objetivos giram em torno de duas questões centrais: "A que insuficiências uma perspectiva discursiva procurou responder?"; e "Em que sentido as práticas da Análise de Conteúdo contribuíram para as reflexões desenvolvidas por uma abordagem discursiva”. Como conclusão, indica-se a pertinência de um debate sobre a problemática relação existente entre texto e contexto.

\section{Abstract}

This paper focuses on the discussion of a discursive approach developped as an alternative to the insufficiencies of Content Analysis. Our goal in centered on two main questions: which are the insufficiencies which motivated a discursive approach; in what sense the practices in Content Analysis contributed to the positions assumed by a discursive approach. The conclusions indicate the need of further research on the unsettled relationship between text and context.

\section{Résumé}

Dans cet article nous essayons de suivre la mise en place d'une perspective discursive à partir des insuffisances témoignées par le travail en Analyse de Contenu. Aussi notre objectif est-il centré sur deux questions majeures: à quelles insuffisances une perspective discursive a-t-elle essayé de répondre; dans quel sens les pratiques de l'Analyse de contenu ont-elles contribué aux réflexions rendues possibles par une approche discursive. Nous concluons sur la pertinence d'un débat sur la nature problématique des rapports qui se nouent entre texte et contexte. 